\title{
Práticas Psicológicas e Dimensões de Significação dos Problemas de Saúde Mental
}

Psychological practices and semantic dimensions of mental health problems

Mônica Lima

Universidade Federal do

Vale do São Francisco

Mônica de

Oliveira Nunes

Universidade

Federal da Bahia

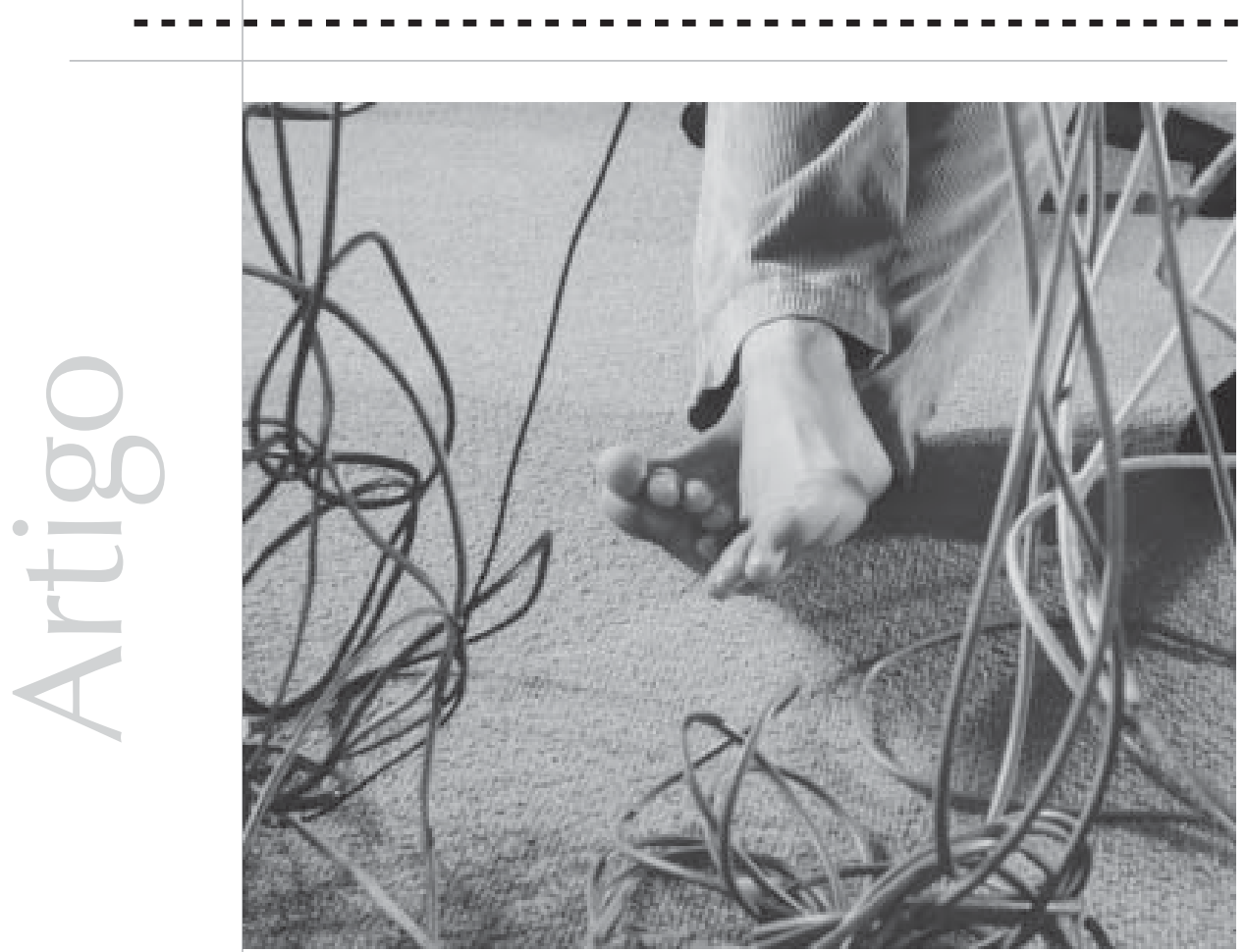




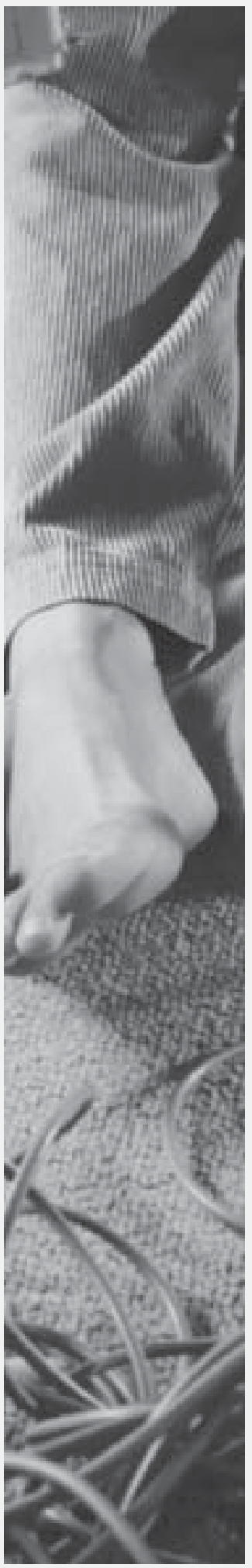

Resumo: Buscou-se compreender como atuam os psicólogos e quais significados atribuem às práticas psicológicas desenvolvidas nos serviços públicos de saúde de Salvador. Utilizou-se o modelo teórico-metodológico de Sistema de Signos, Significados e Práticas. Entrevistaram-se 21 psicólogos dos 24 vinculados à Secretaria Municipal de Saúde, com roteiros semi-estruturados. Observou-se a predominância da oferta de psicoterapia individual com orientação psicanalítica. Discutem-se duas modalidades de práticas psicológicas (psicoterapias e para-psicoterapias), considerandose a inadequação das técnicas psicológicas a uma parte da população distante de um padrão intimista e detalhista de expressar os problemas de saúde. Identificaram-se duas dimensões de significação dos problemas de saúde; a) individual caracteriza-se pela estrutura psíquica do usuário, do tipo e da gravidade da doença; b) coletiva caracteriza-se pelos aspectos socioeconômicos e culturais. A escuta psicológica pode seguir uma tendência mais asséptica ou cautelosa em relação às dimensões identificadas. Discute-se a hipótese de que há seleção socioeconômica e cultural da clientela.

Palavras-Chaves: psicoterapia; saúde mental; serviços públicos de saúde; atendimento psicológico; signos, significados e práticas.

Abstract:The aim of this study was to understand how psychologists perform and what meanings they attribute to the psychological practices developed within the public health services in Salvador. A theoreticmethodological model of systems of signs, meanings and practices was used. Twenty-one psychologists were interviewed from the 24 associated with the Municipal Department of Health, using semi-structured interviews. It was observed that the predominant service was individual psychotherapy based on psychoanalysis. Two types of practices are discussed: psychotherapy and para-psychotherapy. These practices were considered inadequate for part of the population who were distant from a standard of intimacy and detail expressing health problems. Two dimensions of meaning related to health problems were identified: a) individual, characterized by the psychic structure of the patient, the type, and the acuteness of the disease. b) Collective, characterized by the socioeconomic and cultural aspects. Psychological listening could suggest a more aseptic or cautious tendency in relation to the dimensions identified. The study discusses the hypothesis that there is a socioeconomic and cultural selection of the clientele.

Key words: psychotherapy, mental health, public health services, psychological service, signs, meanings, and practices. 
No Brasil, desde a década de 1980, alguns pesquisadores têm estudado a difusão do saber psicanalítico e a constituição da cultura psicanalítica. Estes estudos partem do pressuposto de que o saber psicanalítico surgiu em uma determinada circunstância do individualismo no ocidente, propondo modalidades específicas de agenciamento e de emergência da subjetividade, típicas de sujeitos que se pensam livres e iguais (Figueira, 1987). Esse pensamento é descrito como desempenhando um papel orgânico e fundamental nos valores, crenças e perspectivas ideológicas nos setores médios brasileiros, construindo uma "visão de mundo psicanalítico" (Figueira, 1987).

Neste sentido, a difusão da cultura psicanalítica apresenta um certo "estilo de vida", a princípio, para as classes médias e altas brasileiras, que direciona e dá sentido a aspectos significativos da vida, como as relações amorosas, deliberação de ter e criar filhos, escolha da carreira profissional (Russo, 1993). Na Bahia, como em outros centros urbanos do país, ela esteve limitada àqueles que fazem parte de segmentos médios intelectualizados e que caracterizam uma certa elite social, os quais, por terem maiores condições econômicas e culturais, obtiveram acesso privilegiado aos conceitos, aos debates e aos serviços por ela oferecidos (Silva, 1995).

O efeito da difusão da cultura psicanalítica tanto na vida cotidiana de leigos quanto na própria produção de conhecimento dentro de campos científicos é designado "psicologização" (Figueira, 1988). Russo (2002, p. 43) também descreve a difusão da psicanálise como força motriz para o processo de psicologização da sociedade, um modo de organização da vida psíquica que supõe "a volta para dentro de si mesmo [...] uma busca "dentro de si" para o que antes estava "fora" - parâmetros, regras, orientação".
Em busca de compreender esse fenômeno de psicologização, muitos autores procuraram analisar a crescente difusão do saber psicanalítico-psicológico no cotidiano dos brasileiros nas últimas décadas do século XX, ora focalizando-a nas classes médias urbanas (Velho, 1987; Russo, 1993), ora nas classes populares (Ropa \& Duarte, 1985; Costa, 1989; Bezerra-Junior, 1993). Esses últimos estudos questionam e problematizam a pertinência do atendimento psicológico para uma população que sente, pensa e age a partir de princípios menos individualistas. No entanto, faltam estudos que focalizem as práticas e concepções de psicólogos em um aspecto crucial que é articulação das orientações teóricas com a prática concreta de serviços públicos que se dirigem fundamentalmente às classes populares, particularmente para o contexto baiano.

Um sujeito considerado mais afeito à prática psicanalítica pertence também às classes sociais mais altas e letradas e tem, supostamente, se beneficiado mais com este tratamento psicológico, freqüentemente diferenciando-se de pessoas que pertencem às ditas classes populares (Figueira, 1987; Costa, 1989; Bezerra-Júnior, 1993). Figueira (1987), para explicar a diferença de engajamento das pessoas no tratamento psicanalítico, considera os próprios mecanismos sociais de estruturação de subjetividade e identidade, mais do que o fato de os clientes se pensarem ou não como "indivíduos", ou seja, livres e iguais. O autor inclui em sua análise aspectos da própria interação cotidiana, que ao serem excluídas ou modificadas em favor dos rituais típicos das práticas psicológicas (setting analítico), demarcam diferenças sociais e culturais, às vezes intransponíveis. Ropa \& Duarte (1985) apontam limitações do próprio saber psiquiátrico-psicológico (psicanalítico), falta de 
incentivos institucionais, contradições socioeconômicas entre os profissionais e usuários que explicariam o descompasso entre as demandas da população e as práticas psicológicas oferecidas.

É importante ressaltar que alguns estudos percebem como problemático atribuir necessariamente à Psicanálise a responsabilidade por esse descompasso, uma vez que a mesma tem se constituído como um importante horizonte de compreensão dos problemas de saúde mental. Estudos mais recentes como o de Figueiredo (1997) defende que o dispositivo psicanalítico não foi suficientemente colocado à prova para ser rotulado como ineficaz ou impróprio para atender às demandas da clientela que busca os serviços públicos.

Costa (1989) acredita igualmente que a psicanálise pode ser utilizada como um dos recursos de tratamento para a clientela que busca os serviços públicos de saúde. Ele descreve o encontro de pessoas advindas das classes populares que se queixam de nervoso com os profissionais psi, buscando explicar a "apatia" teórico-técnica presente na concepção clínica. O autor nos adverte quanto a possibilidade reducionista de alimentarmos a confiança na universalidade da classificação nosográfica e de um modelo de representação do aparelho psíquico (Costa, 1989). Além disso, ele destaca a importância de considerarmos que "os distúrbios mentais só existem através de certos conflitos subjetivos, os quais, por seu turno, estão socioculturalmente condicionados" (Costa, 1989 p. 18).

Neste artigo buscamos contribuir de modo singular com este debate nos remetendo a uma abordagem sócio-antropológica, evidenciando os desafios decorrentes do oferecimento de práticas psicológicas para uma população advinda de classes populares, a partir das narrativas dos psicólogos. Nesta direção discutimos os signos e os significados atribuídos às práticas psicológicas desenvolvidas pelos psicólogos de várias orientações teóricas, ressaltando que em sua maioria são psicanalistas, a partir dos dados empíricos da tese intitulada "Atuação Psicológica em Serviços Públicos de Saúde de Salvador: do ponto de vista dos psicólogos" (Lima, 2005). Por fim, é imprescindivel situar o leitor em relação à hermenêutica antropológica que fundamenta a leitura dos dados coletados, em detrimento de outras possibilidades analíticas do campo da psicologia e mesmo da antropologia.

\section{Modelo Teórico-Metodológico}

O trabalho de campo deste estudo ocorreu entre os anos de 2002 a 2003, quando entrevistamos 21 psicólogos dos 24 empregados na assistência direta à população, em cinco UBSs e três CSMs, vinculados à Secretaria de Saúde Municipal de Salvador, Bahia. A coleta e a análise de dados foram inspiradas no modelo teórico-metodológico do Sistema de Signos, Significados e Práticas em Saúde Mental - S/ssp (Bibeau, 1992; Bibeau \& Corin, 1995; Almeida-Filho \& Caroso \& Alves \& Rabelo \& Rodrigues \& Bibeau \& Corin, 1996; Almeida-Filho \& Coelho \& Peres, 1999; Almeida-Filho \& Corin \& Bibeau \& Caroso \& Alves \& Rabelo \& Uchoa \& 2000; Almeida-Filho \& Corin \& Bibeau 2000).

O S/ssp é constituído de três níveis para a abordagem de um problema de investigação: o factual, o narrativo e o interpretativo (Bibeau, 1992). No primeiro nível, factual, parte-se da idéia de que é preciso levantar fatos, eventos e ações concretas significativas para os sujeitos da pesquisa. Além disso, 
[1]. 0 processo interpretativo pode ser entendido a partir de quatro regras básicas apresentadas em aforismos por Bibeau e Corin (1995, p. 55-60). 1) "adquirir familiaridade com a superficie da realidade", traduzido no esforço de ganhar familiaridade com o mundo do nativo, aprendendo sua língua, seus costumes econhecendo suas atividades; 2) "olhar por trás dos cenários e ler nas entrelinhas", ou seja, não se limitar ao que é dado superficialmente, mas descortinar as camadas da realidade, buscando os significados intencionais ou voluntariamente escondidos. Neste sentido, considerando a analogia da cultura como textos (Geertz, 1989) produzidos na interação do pesquisador com e sobre seus informantes, buscaro "subtexto da cultura"; os interstícios, os silêncios e os múltiplos disfarces dos conceitos nativos; 3) "seguir os passos dos adivinhos", retrata dois sentidos: a) a seleção de pessoas, autoridades, contadores de histórias, ou seja, informantes-chaves que se autorizam a narrar suas experiências eque são pessoas conhecedoras do objeto de interesse do pesquisador; além disso: $b$ ) considerar que o processo interpretativo é da mesma natureza da "adivinhação", não no sentido mágico da tarefa, mas que advém da possibilidade do pesquisador conectar os signos por ele selecionados, identificando-os dentro de um sistema de significados oumodo de pensamento que prevalece dentro do grupo estudado; 4) a quarta regra para desenvolver a interpretação antropológica sob bases confiáveis ressalta que cabe ao pesquisador "se comprometer no esforço cooperativo criativo" para compreender a realidade estudada. Neste sentido, é preciso considerar que a interpretação dos textos implica numa cooperação entre o escritor e o leitor (Ricoeur, 1989, p. 1991) que deve ser capaz de preencher os espaços vazios; considerar que os informantes são co-autores ao fornecerem as interpretações nativas. recolher dados complementares diversos, inclusive estatísticos relacionados ao problema. Outro aspecto considerado no nível factual quer ressaltar a importância de tomar como ponto de partida os casos e situações concretas, no sentido de não nos limitarmos às representações meramente abstratas da realidade.

O nível narrativo diz respeito à coleta inicial de relatos espontâneos sobre a problemática e identificação dos interlocutores-chave, que reconstruíram as suas experiências. Ressaltamos que tais narrativas são as principais unidades de análise da proposta, e não os casos propriamente ditos, marcando um outro tipo de delineamento de pesquisa, que não o de estudo de caso advindo da clínica médica e psicológica, ou da corrente sociológica (Bibeau, 1992).

O nível interpretativo implica em considerar as interpretações dos interlocutores enquanto uma interpretação nativa, à qual o pesquisador não pode se limitar. A hermenêutica antropológica requer a passagem da mera descrição dos fatos e modelos explicativos nativos para a elaboração de uma interpretação, ou seja, um trabalho cooperativo analítico que propicie a emergência dos sentidos que podem escapar aos atores sociais (Bibeau, 1992).

Utilizamos o seguinte procedimento para interpretação das narrativas: a) a identificação e agrupamento dos termos utilizados pelos próprios psicólogos na reconstrução de suas trajetórias profissionais; b) a construção de categorias analíticas, considerando os significados que lhes são atribuídos, já que incentivamos relatos de situações concretas de trabalho, desde as abordagens de casos clínicos atendidos, até as descrições do dia a dia do serviço.
A inspiração no $\mathrm{S} / \mathrm{ssp}$ nos conduziu a compartilhar duas questões operacionais: 1) as vantagens de considerar as narrativas produzidas pelos interlocutores (representantes de um campo científico, ou seja, não leigos) como qualquer conhecimento localmente construído, portanto, plural, fragmentado e até contraditório como ponto de partida para a sua compreensão; 2) a idéia de que suas histórias concretas particulares na vivência dos desafios da atuação psicológica não devem ser lidos como "textos autônomos", no sentido de resumi-los a experiências subjetivas e reificar as narrativas (Bibeau, 1992). A hermenêutica antropológica de segundo nível é uma estratégia que combina a submissão ao texto dos discursos coletados e a violência feita pelo pesquisador sobre estes textos[1].

A antropologia interpretativa Geertz (2002) considera que a própria ação é constituída de significados e que pode ser lida como um texto. A inscrição etnográfica possibilita a passagem da mera descrição dos fatos e modelos explicativos nativos para a elaboração de uma interpretação do pesquisador (Geertz, 1989; 2002). No entanto, estamos no lugar de quem "lê" e não de quem "escuta", quando do tratamento dos dados coletados. No primeiro momento, no ato da entrevista tem-se a escuta e a produção de um diálogo com seus informantes-chaves: há uma interpretação, menos consciente, sobre o que é narrado. No segundo momento, a análise das narrativas nos coloca no papel de quem lê, o qual é enriquecido pela prévia participação na produção direta das narrativas, suas unidades de análise, mas que não se limita a este momento nem a tornaria inviável se não houvesse participado da mesma: o dito inscreve-se [2]. 
Nesta perspectiva, ler um texto significa interpretá-lo, ou seja, apropriar-se do estranho, no sentido de diminuir a distância cultural (Ricouer, 1989; 1991). A tarefa da leitura é efetuar a referência para o mundo e para o sujeito, atualizando a ambiência e a audiência. A escrita reivindica a leitura e isto modifica a relação autor-leitor, coloca o leitor no lugar de quem produz uma interpretação seguindo a própria interpretação oferecida no texto.

Para Geertz (2002), a interpretação pode ser também exemplificada como sendo a passagem da experiência próxima à experiência distante. Por experiência próxima entende-se o uso natural e sem esforço de explicações sobre o que os semelhantes vêem, sentem, pensam e imaginam que os demais membros do grupo entenderiam facilmente; por sua vez, a experiência distante é uma outra interpretação, não menos válida do que a anterior, elaborada para alcançar objetivos científicos, filosóficos ou práticos. No terreno da interpretação, ao pesquisador cabe não se limitar à experiência-próxima, mas considerá-la como ponto fundamental de partida. Tomamos os relatos dos nossos interlocutores como produzindo conceitos de experiência-próxima, ainda que, em alguns momentos, eles façam uso de conceitos que vêm de experiência-distante, pois são também especialistas. Esta foi a nossa proposta interpretativa.

\section{Psicoterapias e Para-Psicoterapias: vertentes da atuação psicológica}

Muitos são os termos utilizados pelos psicólogos ao relatarem as atividades que desenvolvem nos serviços públicos de saúde: psicoterapia, psicanálise, psicoterapia de base psicanalítica, psicoterapia breve, orientação, aconselhamento psicológico (individual ou em grupo), acompanhamento psicológico, terapia, terapia breve, (de) apoio, de suporte e de grupo. A despeito do tipo de prática psicológica oferecida, a escuta é considerada a ferramenta principal de atuação e é freqüentemente usada para qualificar e diferenciar sua prática daquelas desenvolvidas por outros profissionais (incluindo os psi). À escuta são atribuídos um caráter refinado, uma certa curiosidade desvelada em um estado de permanente atenção requintada por parte do psicólogo, além de uma ação de alerta e de interesse sobre a fala significativa, que reconstrói a história dos sujeitos, revelada a partir de seus sentimentos, emoções, desejos e conflitos. Os encontros clínicos são descritos como lugares privilegiados de acesso à subjetividade, de busca de autoconhecimento e crescimento. Neste sentido, as práticas psicológicas reivindicam o acesso à subjetividade no processo de saúde-doença-cuidado.

A psicoterapia ocupa um caráter de "ideal de atuação" hierarquicamente superior às demais técnicas terapêuticas oferecidas. $\mathrm{O}$ usuário é sempre recebido pelo psicólogo como um possível candidato à psicoterapia, seja através de encaminhamento do próprio serviço ou da demanda espontânea. A maioria dos psicólogos organiza seu trabalho oferecendo psicoterapia de base psicanalítica; as outras práticas terapêuticas são tidas como variações necessárias e circunstanciais, em certa medida legitimadas quando há impedimentos à realização da psicoterapia. De certa forma, estas últimas são tratadas pelos próprios profissionais como menos importantes, porém mais adequadas ao perfil de uma parcela da clientela, sendo por isso denominadas por nós de para-psicoterapias.

Os psicólogos, ao utilizarem o termo psicoterapia, apresentam os seguintes signos
[2] Este procedimento remete-se as ideais de Ricoeur (1989; 1991) que parte da premissa de que $o$ ato da leitura é diferente do ato do diálogo. Uma característica importante que marca esta diferença é que a escrita preserva o discurso e o torna disponivel para a memória individual e coletiva. O diálogo está para a fala, assim como, a escrita está para a leitura, uma vez que a escrita toma o lugar do discurso. No entanto, não há supremacia entre a fala e a escrita: "o que aparece na escrita é o discurso enquanto intenção de dizer e [...] a escrita é uma inscrição directa desta intenção, mesmo se, histórica e psicologicamente, a escrita começou por transcrever graficamente os signos da fala" (Ricouer, 1989, p. 143). 


\section{[...] eu acho que não chegariam num consultório particular, entendeu? Assim, psicólogo "interferir muito mais" ou ser "mais incisivo" nestes contextos de trabalho é um marcador da diferenciação em relação às atuações realizadas em consultório privado:} todo tipo de patologia, todo tipo de rede familiar que você possa imaginar, e tal, assim, é aí que você percebe que é uma realidade completamente diferente, que você que tem que se adaptar àquele, e não você querer que o paciente se adapte ao seu referencial, entendeu?

Psicóloga 03

Olha, a gente utiliza o referencial, né... é... psicanalítico aqui. E alguns pacientes, dependendo do tipo, da problemática do paciente e da estrutura desse paciente quando eu falo de estrutura, quer dizer estrutura psíquica - eu interfiro muito mais... do que interferiria no consultório, né? [...] uma necessidade - é a palavra exata - de... esse trabalho ser no menor tempo possível. Então, eu tenho que fazer um trabalho mais incisivo e, às vezes, eu sou muito menos... é... psicanalista aqui do que no consultório. e significados atribuídos ao mesmo: terapia de autoconhecimento, de competência exclusiva do psicólogo, realizada a partir dos conteúdos trazidos espontaneamente pelo usuário, baseada na capacidade interna e individual do usuário de adequar-se à produção de um discurso psicológico. Segundo esses profissionais, as psicoterapias que realizam nos serviços públicos não são "análise" nem "psicanálise". O fato do [Psicóloga 02].

Entre outros fatores que influenciam a não realização da "análise" ou "psicanálise" estão os derivados: a) da estrutura institucional inadequada (tipo de sala, falta de divã, etc), mas este tipo de questão é criativamente superada pelo profissional; b) dos dispositivos institucionais (tempo e números de sessão, pressão para alta psicológica e a predeterminação de quantidade de usuários a serem atendidos).

Acho que a gente não tem nenhum... nenhuma estrutura pra fazer um trabalho psicoterápico bom aqui dentro. A gente faz um trabalho, que eu chamo muito mais de uma psicoterapia de apoio. Apesar de a psicoterapia de apoio ser considerada uma psicoterapia breve, eu tenho alguns pacientes que já têm mais de três anos comigo, que eu não vejo condições de mexer, de afastá-los. [Psicóloga 02]

Um terceiro desafio nos parece, no entanto, bem mais significativo: c) a inadequação das técnicas dos psicólogos a uma parte da população que busca os serviços, seja por conta da estrutura psíquica do usuário, das expressões incomuns de sofrimento, das condições socioeconômicas da população e, principalmente, do distanciamento da clientela em relação a um estilo intimista e introspectivo de expressar emoções e sentimentos:

[...] eu acho que não chegariam num consultório particular, entendeu? Assim, todo tipo de patologia, todo tipo de rede familiar que você possa imaginar, e tal, assim, é aí que você percebe que é uma realidade completamente diferente, que você que tem que se adaptar àquele, e não você querer que o paciente se adapte ao seu referencial, entendeu? [Psicóloga 03]

Dois aspectos são importantes de serem destacados em relação à percepção dos entrevistados sobre a realidade e a clientela atendida nos serviços públicos de saúde. O primeiro diz respeito à maior diversidade clínica e de redes familiares mais difíceis de chegarem ao consultório particular. O segundo aspecto está relacionado à necessidade de adaptação da atuação psicológica para dar conta dessa realidade. A maioria dos usuários parece não apresentar determinadas características que favoreçam o engajamento que o trabalho psicológico exige. No relato abaixo, chama à atenção o fato de o profissional ter a necessidade de mexer no 
próprio referencial clínico de base, seja incluindo outras leituras, escolhendo determinadas técnicas em detrimento de outras que julga mais pertinentes, ou mesmo vislumbrando a mudança do referencial teórico para uma outra abordagem teórica incompatível com a anterior para dar conta da diversidade da clientela atendida.

É uma coisa assim que eu até criticava muito [...]o, sempre criticava muito essas pessoas que faziam desse modelo um monte de coisa, mas, ao chegar aqui, eu percebi que eu tinha que me flexibilizar mesmo assim um pouco, porque senão eu não ia tá podendo atender nem 5\% dessa população, né, eu ia tá oferecendo um serviço mui-to elitizado pra o que essa população pede e solicita, tem capacidade assim, às vezes, de compreensão. Então, meu referencial teórico mudou, eu tive que passar a ler outras coisas assim. [Psicóloga 03]

Que mecanismos poderiam estar por trás dessa aparente dissonância entre a orientação teórica dos psicólogos e as demandas dos pacientes? Para desenvolvermos essa discussão, lançaremos mão de Figueira (1978, p. 59) no texto em que ele descreve como as pessoas orientam-se no processo de busca terapêutica frente à diversidade de sistemas simbólicos. Segundo o autor, um sistema simbólico pode ser entendido como uma matriz de "significados socialmente objetivados e subjetivamente reais", na qual a biografia do indivíduo se inscreve. Um sistema simbólico tem caráter "ordenador, fornecendo, ao sujeito que o adote, uma perspectiva coerente para a apreensão subjetiva das diferentes fases de sua biografia". Figueira (1978) identificou três estilos de relação de um sujeito com os sistemas simbólicos: o isolamento, a relativização e a desorientação. Invertendo aqui o sujeito de referência da análise realizada pelo autor dos que buscam o tratamento (usuários) para os que o oferecem (psicólogos), consideramos que os psicólogos têm disponível uma gama de sistemas simbólicos, ainda que circunscrita ao seu próprio campo disciplinar, podendo lançar mão desse arsenal ao se depararem em sua trajetória profissional com questões que dificultam a realização do seu trabalho. Na relação de isolamento, o sujeito se orientaria totalmente por um sistema simbólico específico. Este "fornece ao sujeito uma weltanschauung capaz de dotar o mundo e sua experiência social de sentido e lógica, não deixando brechas por onde possa insinuarse o desconhecido" (Figueira, 1978, p. 63). O estilo de relativização permite que o sujeito mantenha uma relação mais amistosa com outros sistemas. Há "possibilidade de relativizar a própria visão de mundo, captandoIhe os delineamentos, limites, potencial explicativo e vantagens" (Figueira, 1978, p. 64). No outro extremo, temos a desorientação, onde, por motivos os mais diversos, os sujeitos "se encontram impotentes diante da pluralidade, oscilam entre visões de mundo, conjunto de normas e grupos de referência contraditórios, o que vem acompanhado de um estraçalhamento de fidelidade e aliança" (Figueira, 1978, p. 65).

Os profissionais entrevistados, frente aos desafios encontrados para a realização do seu trabalho, podem vir a desenvolver uma certa relativização ou desorientação em relação ao seu próprio sistema simbólico, ao sinalizarem a necessidade de flexibilização e adequação da sua atuação. Uma das hipóteses de Figueira (1978) é que a relação de isolamento do paciente estabelecida com um determinado sistema simbólico aumenta o poder de benefício do mesmo, no que diz respeito ao aproveitamento do tratamento psicológico. A nossa hipótese segue um caminho contrário:
Na relação de isolamento, o sujeito se orientaria totalmente por um sistema simbólico especifico. Este "fornece ao sujeito uma weltanschauung capaz de dotar o mundo e sua experiência social de sentido e lógica, não deixando brechas por onde possa insinuar-se o desconhecido"

Figueira 
Dimensões de significação de um problema de saúde referem-se a um conjunto de aspectos

qualitativamente importantese valorados por quem interpreta um determinado problema de saúde, atribuindoIhes algum significadoe sentido, aos quais podemos

relacionar para compreendermos o problema e as respostas elaboradas para o seu manejo. o estilo de isolamento do profissional pode dificultar ou mesmo inviabilizar o maior ganho psicoterapêutico do paciente, particularmente daqueles que se distanciam do sistema simbólico do terapeuta, já que apostamos que um estilo de relativização pode apurar a sua escuta psicológica, tornando-a mais sensível aos conteúdos socioculturais.

A adoção de um estilo ou outro pode ainda decorrer da percepção do profissional de que há lacunas dentro do seu sistema simbólico e de que neste não há respostas adequadas para a superação de obstáculos interpretativos sobre as experiências de sofrimento dos seus pacientes. No caso de isolamento, seria justificada a introdução de leituras e mesmo de técnicas não propostas pelo seu sistema simbólico de origem, mas complementares; no segundo caso, de desorientação, vislumbrar-se-ia a mudança de um sistema para outro teoricamente incompatível.

A conjugação de fatores destacados acima, que aparecem nas narrativas dos nossos interlocutores, reforça o uso e a importância de uma determinada prática em detrimento de outra. Neste sentido, a princípio as parapsicoterapias [orientação, aconselhamento, terapia breve, (de) apoio, (de) suporte, acompanhamento] correspondem a variações da atuação psicológica "ideal" (psicoterapia). A diferenciação entre tais vertentes tem como pano de fundo a própria cultura psicológica da assistência à saúde mental hierarquizada que coloca todas as outras terapêuticas não medicamentosas como tendo importância e eficácia secundárias ou complementares. Do ponto de vista dos nossos entrevistados, esta diferença sugere ainda um outro nível hierárquico dentro das intervenções psicológicas desenvolvidas pelos psicólogos. Neste caso, decorrente do fato de ser necessário adequar a atuação psicológica em resposta a determinadas particularidades apresentadas pela população atendida: o discurso de muitos usuários sobre os seus problemas de saúde é fortemente marcado por problemas socioeconômicos e culturais específicos.

A nossa hipótese é que, em situações concretas de escuta psicológica, o que pode contribuir para a compreensão da realização de uma prática psicoterápica em detrimento de outra, ou da conjugação de teorias e de técnicas diferentes, parte do modo como os psicólogos lidam e interpretam as dimensões de significação dos problemas de saúde da clientela (Lima, 2005).

\section{Atuações psicológicas: dimensões de significação e função psicoterapêutica}

Identificamos duas grandes dimensões de significação atreladas aos relatos dos psicólogos sobre as práticas psicológicas e, conseqüentemente, fonte potencial de guia da escuta psicológica. Dimensões de significação de um problema de saúde referem-se a um conjunto de aspectos qualitativamente importantes e valorados por quem interpreta um determinado problema de saúde, atribuindo-lhes algum significado e sentido, aos quais podemos relacionar para compreendermos o problema e as respostas elaboradas para o seu manejo. Observamos dois componentes principais que marcam principalmente as atribuições presentes nessa dimensão de significação. Um deles caracterizaria o que chamamos de dimensão individual (psíquica e biológica), definida a partir da estrutura psíquica do usuário (psicótica ou neurótica), ou pelo tipo e gravidade da doença propriamente dita (transtornos mentais leves, moderados e 
graves); geralmente são aspectos que se remetem a interpretações de cunho mais interno dos problemas de saúde. O outro componente diz respeito à dimensão de significação coletiva, melhor caracterizada pelos aspectos socioeconômicos e culturais evidenciados nas interpretações dos psicólogos; a princípio, tudo aquilo a que não se poderia dar respostas clínicas, mas que está em jogo na produção de sentido do sofrimento.

\section{Atuações psicológicas: dimensão de significação individual}

Uma das perspectivas da dimensão de significação individual que orienta a atuação psicológica diz respeito à relação entre o tipo e a gravidade da doença, e não à pessoa doente. Neste sentido, os problemas graves de saúde mental, como as esquizofrenias, as depressões e ansiedades acentuadas seriam tratadas com para-psicoterapias, qualificadas como apoio, orientação ou suporte. Destacamos um dos fragmentos narrativos dos nossos informantes abaixo:

- Psicoterapia como suporte ou apoio Pessoas em... crise muito acentuada, crise de ansiedade muito forte, depressão muito também acentuada, então fazem uso de medicação e a psicoterapia fica mais como um suporte assim, mais como um apoio, né. [Psicólogo 04]

As para-psicoterapias comumente aparecem descritas em situações em que o seu emprego envolve uma função psicoterapêutica secundária quando comparadas à atuação idealizada. Em relatos que as descrevem há também a percepção de que o uso de medicação é um marcador potencial hierárquico que coloca as para- psicoterapias em segundo plano em relação à sua capacidade de trazer benefícios palpáveis aos usuários.

Jucá (2003) discute a relação terapêutica psiquiatra-usuário de ambulatório de um hospital psiquiátrico, do ponto de vista dos primeiros "é visível a tendência de hierarquizar as várias terapêuticas, onde o psiquiatra aparece no ápice e as outras intervenções se caracterizam como trabalhos de 'apoio'" (Jucá, 2003, p. 154). Chama a atenção para a ausência do reconhecimento do trabalho psicológico como um dos elementos compensadores. Paradoxalmente, no discurso dos usuários, há indicativo de ganho terapêutico quando se pode dispor de acompanhamento psicoterápico, interpretado como um espaço de ressignificacão da sua condição de "doente mental", concomitante ao trabalho de manutenção (Jucá, 2003). No entanto, a única menção feita por um dos psiquiatras remete-se à idéia de que o trabalho psicológico, neste caso psicanalítico, pode funcionar como um fator indiretamente descompensador (Jucá, 2003). Tal atributo descompensador foi endereçado ao papel que os pastores tendem a exercer nos usuários em tratamento religioso, os quais seguem seus conselhos interrompendo o uso do medicamento (Jucá, 2003).

Nas falas dos psicólogos entrevistados, há uma tendência de a psicoterapia ser vista como mais indicada para alguns casos específicos, geralmente coincidindo com as demandas trazidas pelos neuróticos, principalmente para os psicólogos que não estão preparados para atender a clientela de psicóticos, que é a maioria dos profissionais. Há casos em que a escuta psicológica é vista como um "apoio", qualificada aqui como para-psicoterapia, mas que não desautoriza um trabalho psicológico, mesmo para psicóticos: 
porque é mais um apoio que eu dou a ela; é uma escuta, claro, eu escuto, ela fala!... Tem um discurso, inclusive, espontâneo, apesar de desorganizado, porque ela tem uma estrutura bem comprometida, mas ela não aceita [interromper, ter alta]. Ela vem toda semana. [Psicóloga 02]

Acompanhando um pouco mais a história dessa paciente, percebemos que ela começou a ser atendida há três anos, tem 33 anos, fez a primeira crise de esquizofrenia aos 19 anos e tem um filho. Foi encaminhada pelo psiquiatra para o tratamento psicológico. Em algum momento foi morar em Arembepe e recomendada pela psicóloga a continuar seu tratamento na cidade para a qual se mudara. Apesar da distância, esta proposta não foi bem aceita pela usuária, que continuou comparecendo ao ambulatório em busca de dar continuidade ao seu atendimento psicológico, sendo acolhida pela psicóloga:

E eu comecei um trabalho com ela e tudo mais... consegui, inclusive, ligar as trompas dela fora daqui, [..] parir todo ano, porque ela não tem nenhuma censura [...] é aquela confusão toda. [...] E chorava e pedia. Eu não ia deixar essa paciente sem atendimento. [...]. Depois do retorno, ela já 'tá comigo tem mais de três anos, porque... e ela não falta! [Psicóloga 02]

Nos relatos acima, percebemos que a psicóloga qualifica o tratamento psicológico como um apoio. Esta adjetivação decorreria do fato de se tratar de uma pessoa com estrutura psicótica, ou por incluir estratégias pouco convencionais à atuação de um psicólogo, por exemplo, a cooperação para viabilizar uma cirurgia de ligadura de trompa? Estimular a produção de discurso espontâneo, apesar de "desorganizado" e desenvolver um acompanhamento sistemático através de "escuta" semanal não dariam a esta atuação psicológica um estatuto de psicoterapia? Não percebemos justificativas que possam vir a qualificar este tipo de atuação psicológica como secundária no tratamento da usuária se não as decorrentes de uma visão reducionista do transtorno mental, que tenderia a desqualificar o cuidado da saúde mental pautado no manejo da subjetividade de transtornos graves.

Há uma tendência, que aparece nas narrativas dos psicólogos, de que a psicoterapia seja mais adequada ao tratamento de neuróticos do que de psicóticos, muito mais pela consciência em relação ao despreparo individual de cada profissional em tratar os últimos. Nesta direção, focalizando o olhar nos usuários "não-psicóticos", encontraremos outro tipo de seleção socioculturalmente orientada em relação aos próprios neuróticos, clientela básica dos psicólogos nos serviços visitados. Esta seleção recai na capacidade de compreensão do tratamento psicológico por parte dos mesmos, que traz subjacente a idéia de que pessoas, por serem "mais informadas e mais esclarecidas", estariam mais aptas à psicoterapia. É possível que esta "seleção" esteja operando por causa da confusão entre competência psicológica e a capacidade universal de expressar conflitos psíquicos (Bezerra-Júnior, 1993). Confusão revelada pela expectativa do profissional de que haja, por parte do usuário, a capacidade de descrição detalhista e minuciosa dos sentimentos e emoções associados ao sofrimento e à tendência de buscar explicações fora do aparente, recorrendo ao seu mundo interno, típica da competência psicológica (Costa, 1989).

Nesse particular, entra em jogo mais explicitamente a segunda perspectiva 
atribuída à dimensão individual: é a pessoa, e não só a doença, que define o sentido atribuído às práticas psicológicas. O significado atribuído à prática ocorre a partir da capacidade individual do sujeito, ou da sua competência psicológica, podendo, então, exercer função psicoterapêutica principal. Nas narrativas dos entrevistados, a descrição de pessoas que supostamente têm demanda psicológica, ou competência psicológica, para a psicoterapia, inclui as seguintes características: "passar da queixa à demanda"; "ter determinado nível de questionamento, aprofundamento"; "ter insight"; "trazer conteúdos para serem trabalhados"; "busca o potencial que tem dentro dele"; "se questiona"; "interesse de fazer uma auto-avaliação"; "compreender melhor as coisas"; "buscar o autoconhecimento"; "capacidade para elaborações".

As narrativas abaixo são exemplares em descrever que o tipo de prática oferecida está em função de determinadas características da pessoa, que, se não conduzem a explicações deterministas, ao menos trazem subjacentes uma associação que buscamos aqui explicitar. As para-psicoterapias (orientação, acompanhamento e terapia breve, etc) são oferecidas para os menos aptos a uma produção discursiva de estados emocionais e sentimentos e são assim relacionadas pelos psicólogos:

\section{- Terapia breve}

Olha, no Serviço Público a gente não trabalha... a gente trabalha com uma abordagem psicanalítica, mas a gente não trabalha com psicanálise, tá. A gente introduz a psicanálise, mas, aqui não tem nem um espaço físico que permita isso, né, e também, [diz o nome da entrevistadora], você sabe, fazer um tipo de terapia com um aprofundamento maior, exige o quê, um nível intelectual, um nível de associação mais elaborado, que a nossa clientela nem sempre apresenta. Outra coisa é o tempo que a gente tem aqui, de um ano. Então de um ano, a gente tem que fazer uma terapia breve, a gente não pode focar na questão principal que é a que o usuário traz [...] A: Mas sem descartar o inconsciente. [Psicóloga 06]

Elas evidenciam ainda que a psicoterapia requer, como condição para sua realização satisfatória, a presença de pessoas com maior capacidade de associação de idéias, que tenham nível intelectual elevado, o que, segundo alguns informantes, não coincide necessariamente com maior nível econômico.

tem outras pessoas que têm escolaridade básica, ou nenhuma e que ficam também. Eu acho que é uma coisa muito mais, assim, interna, da formação do sujeito, da pessoa, do questionamento, da relação que teve com a vida pregressa, familiar, com a família de origem. [...] claro que o nível intelectual entra também, mas eu não generalizaria, não diria que é por isso. [...] eu atendo, uma senhora; ela é lavadeira, não teve nem primeiro grau, é uma pessoas super sofrida, veio do interior, né?! uma coisa muito delicada a situação dela, e ela tem, assim, uns insights fantásticos, ela tem umas colocações muito boas, ela se questiona, ela é muito envolvida no trabalho, no atendimento, comprometida mesmo. [Psicóloga 07]

Tais ponderações feitas pelos entrevistados sobre como os aspectos socioeconômicos determinam a natureza e a expressão do sofrimento psíquico demonstram a complexidade que envolve a qualificação da escuta psicológica e exigem a relativização de como os critérios que compõem cada 
uma das vertentes aqui definidas mantêm entre si uma espécie de borrosidade mais do que de determinação unilateral. Nesta direção, na narrativa destacada acima, podemos também perceber que há pessoas que não têm escolaridade alta, mas que conseguem permanecer e obter benefícios do processo psicoterápico. Há, ainda, em algumas narrativas, a preocupação de tomar vários aspectos como conjugados e não atribuir a adesão e a melhora de um paciente a um motivo isoladamente. No entanto, é visível a tendência de atribuir os benefícios psicoterápicos a uma certa capacidade interna da pessoa de lidar com os seus problemas, que particulariza um dado modo de se relacionar com o contexto familiar e com a sua vida pregressa, como mais importantes para a adesão à psicoterapia. Para alguns entrevistados, o comprometimento psíquico ou físico acentuado do usuário pode desautorizar qualquer intervenção psicológica, no sentido de ganho psicoterapêutico, ao menos no sistema ambulatorial:

Eu tenho poucos pacientes que eu posso dizer que estão em processo de psicoterapia, tenho alguns em acompanhamento psicológico, a maioria, mas no processo de psicoterapia, de se comprometer de vir e tal são poucos mesmo. [...] Eu acredito que aqui a gente atende uma parcela da população com, eu acho que talvez o menor nível econômico e educacional de Salvador, que é a população do subúrbio, então não é só a questão de ser público, é questão de ser mesmo... a total ausência às vezes de um hábito ou de um interesse de fazer, de fazer uma auto-avaliação, de compreender melhor as coisas, um nível de alienação mental muito grande, [...] talvez se adequem mais a uma TO [terapia ocupacional], a uma oficina, alguma coisa assim. Porque é uma psicoterapia que, muitas vezes, a gente dá início, mas a gente percebe que não vai ter um rendimento muito grande e aquele paciente acaba abandonando mesmo, é o que acaba acontecendo mesmo com boa parte dessa população. [Psicóloga 03]

Todos os psicólogos consideram a dimensão biológica do sofrimento como garantia de que é preciso intervenção medicamentosa para diminuir o sofrimento; às vezes, a intervenção medicamentosa é condição sine qua non para entrada dos usuários com problemas psíquicos graves no trabalho psicológico. Por outro lado, do ponto de vista dos psicólogos, depois do emprego do trabalho psicológico, a suspensão ou diminuição dos psicofármacos é um marcador da melhora do paciente e da eficácia do processo psicoterapêutico.

Outro aspecto que merece especial consideração é o fato de existir uma propensão à mudança do perfil da clientela atendida pelos psicólogos nos serviços visitados, descrita como uma "demanda diferenciada". Neste particular, observa-se que há uma inclusão mais recente da "classe média empobrecida", ou pessoas "mais esclarecidas", que têm buscado atendimento psicológico nos serviços públicos de saúde, considerada mais apta à psicoterapia. Introduz-se aí, com mais evidência, a dimensão social da seleção dos pacientes para esse tipo de atendimento.

\section{Atuações Psicológicas: Dimensão de significação coletiva}

A dimensão de significação coletiva inclui os aspectos socioeconômicos e culturais dos problemas de saúde, que podem ser percebidos como qualitativamente relevantes para a compreensão dos mesmos. Em sua 
perspectiva socioeconômica, é interpretada pelos interlocutores como um entrave às práticas psicológicas. Neste sentido, a atuação psicológica oferecida nos serviços públicos de saúde visitados não teria função psicoterapêutica:

tem muito caso, até mesmo pela região muito pobre, então tem muito caso que a gente vê é que uma pessoa tá encaminhada, muitas vezes não é nem a questão da psicoterapia, mas a questão é de fome, questão de falta de trabalho, da dignidade mesmo... [Psicóloga 05]

A narrativa abaixo traz uma descrição muito emblemática sobre a determinação do contexto socioeconômico desfavorável de uma família para o comprometimento do desenvolvimento psicológico de uma criança. Destacamos a percepção da psicóloga sobre o limite da atuação psicológica oferecida para lidar com o problema de saúde, que tem como palco um contexto típico de uma parcela das classes populares. O foco da intervenção psicológica acaba se restringindo a torná-la mais resignada, no sentido de conviver com a falta de amor da mãe, que não tem tempo de demonstrar esse sentimento dada a sua condição de trabalhadora pobre. O significado atribuído à dimensão social é restritivo e determinista em relação à sua influência sobre o estar no mundo de pessoas que pertencem às classes populares:

E tem uma coisa assim, que é uma questão social séria, que muitas vezes durante este tempo, me dá meio desespero, assim! Porque você não tem muito o que fazer. Você alerta os pais, você orienta os pais, você discute, trabalha com eles a questão da relação paifilho, mãe-filho. Mas, e aí? Ele não tem a condição de melhorar isso, porque não tem tempo, a mãe chega em casa de noite, vai fazer o quê? Vai cozinhar para o outro dia, vai fazer isso, isso e aquilo. Qual é o tempo que a mãe tem de colocar o filho do lado, deitar a cabecinha no colo "e aí, filho, o que quê você fez hoje?" [...] O que eu tenho trabalhado, aqui, é pra ela conviver bem com isso. Saber conviver com essas questões, mas... ele vai sentir falta, vai sentir falta, vai ficar essa defasagem, vai ficar defasado, vai sentir essa falta de amor, de carinho, de atenção. Eu não sei como é que vai ser isso, não é, mais tarde? [Psicóloga 08]

Muitos dos fragmentos resumem o sofrimento psíquico a uma única dimensão, às vezes dando ênfase à biológica, e em outras à psíquica, em detrimento da importância do contexto social como constituinte desse sofrimento; este é visto como determinante de uma condição imutável. Há ainda, para a dimensão de significação coletiva, um outro aspecto que diz respeito a expressões culturais de sofrimento distantes da visão de mundo psicologizada, que autorizam uma escuta psicológica muitas vezes truncada, quando não a desautorizam totalmente. No primeiro caso, o psicólogo tenta aproximar o "texto" trazido pelo usuário de descrições mais conhecidas, a exemplo do discurso do deprimido, mas que não parece trazer muitos ganhos para o processo psicoterapêutico:

essa depressão, que elas chamam de um nervoso, vamos dizer assim, né, todo esse texto, eu tô sentindo um nervoso. Esse nervoso indefinido, que eu acho que é mais uma coisa depressiva, que é a minha clientela básica (risos) [...] agora eu não sei identificar um caso, ou um exemplo. Mas é muito assim, mulheres que não sabem o que fazer da sua vida, que não, que tão angustiadas, porque tão em casa e aí, maridos, né, que bebem, ou que têm a vida deles, ou que têm outra tem muito caso, até mesmo pela região muito pobre, então tem muito caso que a gente vê é que uma pessoa tá encaminhada, muitas vezes não é nem a questão da psicoterapia, mas a questão é de fome, questão de falta de trabalho, da dignidade mesmo...

Psicóloga 05 
mulher, entendeu? Então a vida delas se resume a quê, né, a cuidar da casa, dos filhos, né, não têm um parceiro, enfim... ou quando tem, às vezes têm um parceiro mais legal e tudo, elas sentem um vazio que não sabem explicar por quê, entendeu? Aí acham que é porque deixaram de estudar, deixaram de ter uma profissão, entendeu, abriram mão da vida, enfim... Enfim, eu acho que é uma coisa que a gente já sabe, né, que é a falta de perspectiva mesmo... Mas, o que é que eu teria mais pra falar sobre isso, que eu não sei? (risos) [Psicóloga 09].

Outro aspecto que chama atenção é o fato de ser tão difícil para esta psicóloga relatar um único caso destes que ela tenha acompanhado, ainda que sejam essas mulheres as que mais lhe procuram. Nesta perspectiva, é razoável inferir que a entrevistada parece tomar os discursos de sofrimento das usuárias que atende excluindo qualquer outra possibilidade de significação que esteja além das suas dificuldades concretas de vida; os conteúdos trazidos pelas suas pacientes não fazem sentido para a escuta oferecida. Nessas situações, quando não é possível a ancoragem de um texto menos familiar em um outro mais conhecido, pode haver a criação de uma nova categoria, como por exemplo, os discursos de sofrimento serem rotulados como "neuroses de dona de casa":

A gente percebe muito aqui no ambulatório aquelas neuroses das donas de casa, aquela "ah doutora, eu não durmo, porque meu marido está com outra", "eu não durmo, porque meu filho sei lá o que, eu não sei mais o que fazer". Outras coisas assim. [Psicóloga 09]

A "neurose de donas de casa" como categoria etnográfica, encontrada entre os nossos interlocutores, padece do mesmo mal das "neuroses sociais" descritas por Nunes (1993). A princípio, este tipo de expressão de sofrimento, nervoso ou neuroses de dona de casa, tende a ser desqualificado pelos profissionais psi. Alguns dos chavões que se pode ouvir são que tais pessoas "só fica[m] na queixa" ou "não têm demanda", ou seja, não conseguem ter um nível profundo de questionamento. Na literatura antropológica, o nervoso é considerado um idioma cultural típico das classes populares (Duarte, 1986; Costa, 1989; Bezerra-Júnior, 1993; Silveira, 2000). Segundo Silveira (2000), ouvindo mulheres nervosas que buscavam atendimento em serviços públicos de saúde, numa cidade ao sul do Brasil, o nervoso pode ser entendido como um idioma com usos e finalidades importantes para a conduta médica. A escuta do idioma do nervoso pôde revelar experiências semanticamente significativas e criadas dentro de redes de interação social particulares, sendo possível destacar papéis e funções sociais que sustentam a vida das pessoas, incluindo as experiências de sofrimento. As queixas de nervoso remeteram à opressão da ou na vida diária, problemas da sexualidade, dificuldades de relacionamento social, entre outros, justificando a pertinência em relacionar suas causas aos seus significados, reafirmando que a doença não é um acontecimento meramente biológico, mas um acontecimento que demonstra uma conjuntura pessoal, social e política adversa. Ainda em alguns relatos aparece uma visão reducionista da complexa relação entre conteúdos religiosos e a expressão de sofrimento psicológico como tendo caráter eminentemente psicopatológico. Tal associação tende a inviabilizar um maior poder interpretativo do conflito psicológico, mesmo quando os conteúdos mágico-religiosos foram emitidos por pessoas com estrutura psíquica menos comprometida. A nossa hipótese é de 
que as pessoas que sofrem de nervoso, e que sofrem por conseqüência de olhado, ou outras nosologias populares, constroem seus "textos" alicerçados em uma visão de mundo pouco individualista, por isso pouco sensível aos ouvidos inadvertidos dos psicólogos. Aparece, na descrição dos casos clínicos relatados pelos entrevistados, a dificuldade de escutarem um discurso muito diferente do que estão acostumados a receber na clínica particular. A busca de supervisão clínica demonstra o empenho de alguns psicólogos e a própria necessidade de estarem mais atentos a esses impasses:

Não, mas eu acho assim, poxa, eu tenho que dar a uma pessoa, que não pode me procurar a nível particular, a mesma qualidade no atendimento que eu dou a uma que pode. Eu não me permito fazer essa diferença. Que eu acho que você, tipo... Eu tinha um colega aqui que ele dizia: "[diz seu nome], mas eu não vou atender a essa senhora, porque ela não sabe nem falar. Ela só vem falar que não tem dinheiro, que ela... das questões sociais dela". Aí ele virou para mim e, esse colega meu que dava supervisão aqui, falou assim: "e ela não tem... você... ela não merece ser ouvida por conta disso?", entendeu? Ela merece o mesmo nível de atenção que você dá a um que consegue um nível de elaboração, que ela não tem, ela não alcança. Tá... ouvir as questões sociais, você tá tratando essa pessoa. Você está tratando dentro dos limites dela. [Psicóloga 09].

Fica evidente a dificuldade de atribuir sentido aos conteúdos culturais para a construção de diferentes modos de expressão da subjetividade. Não seriam o "nervoso", ou as "neuroses de dona de casa", ou o sofrer de "olhado", maneiras de sentir, pensar e produzir, provenientes de modelos diferentes de subjetividade? Quais as vantagens de se considerar tal hipótese? A partir do modo como os psicólogos escutam as dimensões de significação dos problemas de saúde, identificamos que há duas vertentes da escuta psicológica assumidas em tais situações concretas de escuta: 1) a primeira vertente, a escuta cautelosa, é aquela cuidadosa e prudente, que inclui as "impurezas" no sentido de compreender a visão de mundo daquele que produz a fala, considerando a competência psicológica (Bezerra-Junior, 1993) como marcador social e não como selecionador da clientela; 2) a segunda vertente, a escuta asséptica, que elimina, a priori, conteúdos "psicologicamente pouco refinados", está marcada pela miopia etnocêntrica (Costa, 1989). É justamente aquela que não encontra função psicoterapêutica nas experiências de sofrimentos onde incidem fortemente tais particularidades das dimensões de significação que se apresentam no discurso de parte dos usuários que buscam os serviços públicos de saúde visitados, sugerindo que há uma seleção socioeconômica e culturalmente da clientela.

\section{Considerações finais}

Distinguimos duas vertentes de atuação psicológica: as psicoterapias e as parapsicoterapias, considerando o modo como os psicólogos lidam em situações concretas com as dimensões de significação dos problemas de saúde apresentados pelos usuários que buscam atendimento psicológico. A psicoterapia ocupa um caráter de "ideal de atuação" hierarquicamente superior às demais atividades. As para-psicoterapias, ainda que toscamente, parecem-nos um reflexo de uma tentativa de não excluir definitivamente uma grande parte das pessoas que buscam os serviços públicos de saúde, pouco afeitas ao tipo de "refinamento" da psicoterapia. Parece- 
nos uma possibilidade truncada de absorver pessoas em cujo discurso aparecem, mais explicitamente, elementos socioeconômicos e culturais distantes de um certo modelo interpretativo do sofrimento psíquico tomado com padrão. Nesta direção, observamos que a escuta psicológica ora assumia uma tendência cautelosa, ora asséptica. A escuta psicológica dá ênfase à dimensão individual, atribuindo-lhe maior função psicoterapêutica, tende a desqualificar a dimensão coletiva, que escapa ao jogo da produção de sentido do sofrimento. Tais modalidades referem-se, grosso modo e respectivamente, a uma postura profissional psicoterapêutica mais ou menos sócio-culturalmente sensível. 
Professora Adjunta da Universidade Federal do Vale do São Francisco (UNIVASF).

Psicóloga e Doutora em Saúde Coletiva pelo Instituto de Saúde Coletiva/UFBA

Rua Nelson Galo. № 256 Ed. Aida Nunes. Rio Vermelho. Salvador-Bahia.

E-mails:molije@hotmail.com Telefone: 71-81197638

Mônica de Oliveira Nunes

Professora Adjunta do Instituto de Saúde Coletiva - UFBA

Psiquiatra e Doutora em Antropologia Médica pela Universidade de Montreal Rua Sotero Monteiro, 207, ap. 401, Pituba. CEP41820-050, Salvador, Bahia

E-mail: nunesm@ufba.br Telefone: (71)3263-7435

Recebido 06/10/05 Reformulado 27/04/06 Aprovado 26/06/06

Almeida-Filho, N. \& Coelho, M. T. \& Peres. M. F. T. (1999). Conceito de Saúde Mental. Revista da USP, 43, 100-125.

Almeida-Filho, N. \& Caroso, C. \& Alves, P. \& Rabelo, M. \& Rodrigues, N. \& Bibeau, G. \& Corin, E. (1996). Signos, significados e práticas em saúde mental: desafio metodológico e experiência de campo. Não-Publicado, Salvador, Universidade Federal da Bahia

Almeida-Filho, N. \& Corin, E. \& Bibeau, G. (2000). Rething transcultural approaches to mental health research: from epistemology to methodology. Não-Publicado, Salvador, Universidade Federal da Bahia.

Almeida-Filho, N; Corin, E; Bibeau, G; Caroso, C; Alves, P; Rabelo, M; Uchoa, E. (2000). Signs, meanings and practices in mental health: part II. Methodologycal apllication the Bahia study. Não-Publicado, Salvador Universidade Federal da Bahia.

Bezerra-Junior, B. (1993). Grupos: cultura psicológica e psicanálise. Em A. Lancetti. Grupos e coletivos. SaúdeLoucura. São Paulo: Hucitec. p. 129144

Bibeau, G. \& Corin, E. (1995). Beyond tex textuality. Ascetism and violence in anthropological interpretation approaches to semiotics series. Berlin, Mounton De Gruyter.

Bibeau, G. (1992, julio). ?Hay uma enfermedad em las americas? Outro camino de la antropologia médica para nuestro tiempo. Trabalho apresentado no VI Congreso de Antropologia em Colombia. Universidad de los Andes: Santa Fé de Bogotá.

Costa, J. (1989). A psicanálise e o contexto cultural: imaginário psicanalítico, grupos e psicoterapias. Rio de Janeiro: Francisco Alves.

Duarte, L. F. (1986). Da vida nervosa nas classes trabalhadoras urbanas. Rio deJaneiro:Zahar.

Figueira, S. (1988) (org). Efeito Psi: a influência da psicanálise. Rio de Janeiro: Campus.

Figueira, S. (1978). Notas introdutórias ao estudo das terapêuticas I: LéviStrauss e Peter Berger. Em S. Figueira (coord.) Sociedadee Doença Mental. Rio de Janeiro. Campus. p. 47-83.

Figueira, S. A. (1987). O papel da psicanálise no entendimento da construçãa da subjetividade. Em M. Almeida. (org.) Pensando a família no Brasil da colônia à modernidade. Rio de Janeiro: espaço e Tempo. p. 89-100.
Figueiredo, A C. (1997). Vastas confusões e atendimentos imperfeitos: a clinica psicanalítica no ambulatório público. Rio de Janeiro: RelumeDumará

Geertz, C. (1989). A interpretação das culturas. Rio de Janeiro: LTC.

Geertz, C. (2002). O saber local: novos ensaios de antropologia interpretativa. 5 ed. Petrópolis: Vozes.

Jucá, V. J. (2003). Os Sentidos da Cura em Saúde Mental. Tese de Doutorado Não-Publicada, Curso de Pós-Graduação em Saúde Coletiva, Instituto de Saúde Coletiva, Universidade Federal da Bahia.

Lima, M. (2005). Atuação Psicológica em Serviços de Saúde de Salvador: do ponto de vista dos psicólogos. Tese de Doutorado NãoPublicada, Curso de Pós-Graduação em Saúde Coletiva, Instituto de Saúde Coletiva, Universidade Federal da Bahia.

Nunes, M. (1993). Da clínica à cultura: uma etnografia da relação terapêutica no contexto "psi" na Bahia, Brasil. Dissertação de Mestrado Não-Publicada, Departamento de Medicina Comunitária, Universidade Federal da Bahia.

Ricoeur, P. (1991). From text to action: essays in hermeneutics, II. Evanston, Illinois: Northwestern University Press.

Ricouer, P. (1989). Do texto a acção: ensaios de hermenêutica II. Portugal: Rés-Editora.

Ropa, D. \& Duarte, L. F. (1985). Considerações teóricas sobre a questão do "atendimento psicológico às classes trabalhadoras". Em S. Figueira, S. (org.) Cultura da Psicanálise. São Paulo: Brasiliense. p. 178-201.

Russo, J. (1993).O corpo contra palavra: terapias corporais no campo psicológico dos anos 80. Rio de Janeiro: Editora UFRJ.

Russo, J. (2002). O mundo psi no Brasil. Rio de Janeiro: Zahar.

Silva, M.V. (1995). A emergência da cultura psicológica na Bahia: do pré-psiquiátrico ao pós-psicanalítico, cursos e percursos de uma trajetória. Tese de Doutorado Não-Publicada, Curso de PósGraduação em Saúde Comunitária, Instituto de Saúde Coletiva, Universidade Federal da Bahia.

Silveira, M. (2000). O nervo cala, o nervo fala a linguagem da doença. Rio de Janeiro: Fiocruz.

Velho, G. (1994). Individualismo e Cultura: notas para uma antropologia da sociedade contemporânea. Rio de Janeiro: Zahar. 